\title{
Positive correlation between Merkel cell polyomavirus viral load and capsid-specific antibody titer
}

\author{
Diana V. Pastrana $\cdot$ Ulrike Wieland • \\ Steffi Silling • Christopher B. Buck • \\ Herbert Pfister
}

Received: 8 February 2011 / Published online: 26 May 2011

(C) The Author(s) 2011. This article is published with open access at Springerlink.com

\begin{abstract}
Merkel cell polyomavirus (MCPyV or MCV) is the first polyomavirus to be clearly implicated as a causal agent underlying a human cancer, Merkel cell carcinoma (MCC). Infection with MCPyV is common in the general population, and a majority of adults shed MCPyV from the surface of their skin. In this study, we quantitated MCPyV DNA in skin swab specimens from healthy volunteers sampled at different anatomical sites over time periods ranging from 3 months to 4 years. The volunteers were also tested using a serological assay that detects antibodies specific for the MCPyV virion. There was a positive correlation between $\mathrm{MCPyV}$ virion-specific antibody titers and viral load at all anatomical sites tested (dorsal portion of the hands, forehead, and buttocks) (Spearman's $r$ 0.644, $P<0.0001)$. The study results are consistent with previous findings suggesting that the skin is primary site of chronic MCPyV infection in healthy adults and suggest that the magnitude of an individual's seroresponsiveness against the MCPyV virion generally reflects the overall MCPyV
\end{abstract}

The authors D. V. Pastrana and U. Wieland contributed equally to the work.

Electronic supplementary material The online version of this article (doi:10.1007/s00430-011-0200-7) contains supplementary material, which is available to authorized users.

D. V. Pastrana - C. B. Buck $(\bowtie)$

Laboratory of Cellular Oncology, National Cancer Institute,

NIH, Building 37 Room 4118. 9000 Rockville Pike,

Bethesda, MD 20892, USA

e-mail: BuckC@mail.nih.gov

U. Wieland $(\bowtie) \cdot S$. Silling $\cdot$ H. Pfister

Institute of Virology, University of Cologne,

National Reference Center for Papilloma- and Polyomaviruses,

Fuerst-Pueckler-Strasse 56, 50935 Cologne, Germany

e-mail: Ulrike.Wieland@uni-koeln.de
DNA load across wide areas of the skin. In light of previous reports indicating a correlation between MCC and strong MCPyV-specific seroresponsiveness, this model suggests that poorly controlled chronic MCPyV infection might be a risk factor in the development of MCC.

Keywords $\mathrm{MCV} \cdot \mathrm{MCPyV} \cdot$ Merkel cell polyomavirus · Neutralization · Viral load · Skin

\section{Introduction}

Merkel cell polyomavirus (MCPyV or MCV) is a newly identified member of the viral family Polyomaviridae. It is a small, non-enveloped, double-stranded DNA virus. $\mathrm{MCPyV}$ was originally detected in Merkel cell carcinoma (MCC) [1], a rare but highly lethal form of skin cancer. $\mathrm{MCPyV}$ infection is thought to be very common among healthy subjects, with an overall seroprevalence of $42-88 \%$ [2-5].

More extensively studied human polyomaviruses, such as BKPyV and JCPyV (also known as BKV and JCV), also have a high seroprevalence in healthy human adults. Both BKPyV and JCPyV can persist in the stratified epithelium of the lower urinary tract, and periodic reactivation of the infection can result in urinary shedding of virions [6-8]. Viral shedding increases with age, and the incidence of viruria among elderly individuals can reach $70 \%$ for JCPyV and $44 \%$ for BKPyV [9-12]. The similar agerelated increase in MCPyV seroprevalence among healthy adults [2,5] along with its presence in diverse anatomical surfaces such as the skin, aerodigestive, and genitourinary tracts [13-15] suggests that MCPyV may, like BKPyV and JCPyV, often establish a persistent infection in stratified epithelial tissues of healthy adults. 
Although seroresponsiveness to the MCPyV VP1 capsid protein is common among healthy adults, MCC patients tend to show unusually strong seroresponses against the viral capsid [2-4]. We have previously speculated that the strong MCPyV-specific seroresponsiveness of MCC patients might reflect a period of unusually high MCPyV viral load in these patients. A direct correlation between viral load and antigen-specific antibody titers has been inferred for BKPyV and JCPyV infections [16-18] and in several other viral infections, including Epstein-Barr virus [19] human T-lymphotropic virus type-I [20] and influenza virus H1N1 [21]. However, in other types of viral infections, there is an inverse correlation between viral load and neutralizing antibody titers, e.g., Crimean-Congo hemorrhagic fever virus [22] and hepatitis $C$ virus [23]. Thus, the proposed correlation between individual subjects' $\mathrm{MCPyV}$ viral burden and $\mathrm{MCPyV}$-specific antibody titers remains speculative. In this study, serum samples and surface swab specimens from the foreheads, hands and buttocks of healthy volunteers were assayed quantitatively, with the primary goal of determining whether there is a correlation between the magnitude of individual subjects' MCPyV DNA load and MCPyV-specific seroresponsiveness.

\section{Materials and methods}

\section{Volunteers and samples}

Forty-seven healthy adults were invited to participate in the study as volunteers. Subject ages ranged from 24 to 79 years (mean 44.7, median 42). Thirty-one participants were women, and 16 were men. Informed consent was obtained from each participant. Additionally, serum from an 8-year-old male from whom skin swabs were available from a previous study (24) was included (ID-A9); the latter serum was obtained as a byproduct of samples drawn to obtain serum titers after routine vaccinations. Both parents consented to its use in this study. The study protocol was approved by the ethics review board of the University of Cologne, and the study was conducted according to the Declaration of Helsinki principles. There were two cohorts of volunteers, one with 16 volunteers (cohort A) and one with 33 volunteers (cohort B). Cohort A was a subset of volunteers described in a previous report [24]. One female volunteer participated in both cohorts (number 14 in cohort A is the same individual as number 29 in cohort B), but independent swabs and sera were collected for the studies. In cohort $\mathrm{A}$, each participant had been requested to selfswab three anatomical sites: (1) forehead (2) the dorsal surface of the hand, and (3) the buttocks. Volunteers performed 1-10 swabs at each site over a period of up to 4 years (24). For cohort B, one of the authors swabbed the foreheads and hands of volunteers. For each cohort B volunteer, swabbing was performed at 4 different time points that spanned an interval of 3-5 months (mean 3.6), with each swab being separated from the previous one by 15-74 days (mean 44). Volunteers from both cohorts donated one or two serum samples. In instances where two samples were available, they were collected 11-15 months apart. Serum samples were heat inactivated at $56^{\circ} \mathrm{C}$ for $30 \mathrm{~min}$ and stored at $4^{\circ} \mathrm{C}$ until assayed.

\section{Determination of viral load}

DNA was extracted from the swabs as previously described [24] using a QIAamp DNA mini kit (Qiagen, Germany), as directed by the manufacturer. Quantitative real-time PCR (qPCR) was performed as described by Sihto and colleagues [25], except that the elongation time was reduced to $5 \mathrm{~s}$ using a LightCycler 480 Real-Time PCR system (Roche). Beta-globin was used to normalize the samples using Roche's Light Cycler Control Kit DNA. The viral load is expressed as the number of MCPyV DNA copies divided by the number of beta-globin gene copies in $5 \mu \mathrm{l}$ of extracted DNA, respectively. The limit of detection of the assay was defined as 0.002 (i.e., 1 copy of MCPyV DNA per 500 copies of beta-globin). When beta-globin was detectable, swabs contained between 20 and 186,920 (mean 3,763, median 580) copies of beta-globin in $100 \mu \mathrm{l}$ of total extracted DNA. Samples in which MCPyV DNA was not quantitatively detected were arbitrarily assigned a value of 0.001 for graphical display.

\section{Quantitation of MCPyV capsid-specific antibodies}

Serum was analyzed for the presence of MCPyV-specific neutralizing antibodies using a reporter vector-based assay that has been previously described [3]. Detailed protocols for reporter vector production and neutralization assay methods are available at (http://home.ccr.cancer.gov/LCO). Briefly, MCPyV-based reporter vectors (pseudovirions) were produced by transfecting 293TT cells [26] with plasmids pwM and ph2 m, expressing codon modified MCPyV VP1 and VP2 structural genes, along with the reporter plasmid phGluc. Plasmids used to produce viral stocks are available from Addgene (http://www.addgene.org). Viral stocks were purified from the lysates of transfected cells by ultracentrifugation through iodixanol (Optiprep, Sigma) gradients. Heat-inactivated sera were diluted 1:100 and subjected to four-fold serial dilution. The diluted sera were mixed with reporter vector stock for $1 \mathrm{~h}$ at $4{ }^{\circ} \mathrm{C}$ and used for transduction of 293TT cells that were seeded at 30,000 cells per well in 96-well plates. The assay used a reporter vector dose of $80 \mathrm{pg}$ of VP1 per well. After $72 \mathrm{~h}$, conditioned culture supernatants were assayed for luciferase activity 
using a Gaussia Luciferase Assay Kit (NEB) as instructed by the manufacturer. Prism software (Graphpad) was used to calculate the $50 \%$ neutralizing dilution $\left(\mathrm{EC}_{50}\right)$ and the 95\% confidence interval for each serum sample.

\section{Statistical analysis}

Prism software (Graphpad) was used for all analyses. We determined whether data were normally distributed using D'Agostino \& Pearson omnibus K-squared test. Because neither the MCPyV DNA load data sets nor the MCPyVneutralizing titer data sets displayed a normal Gaussian distribution, it was necessary to use a non-parametric test to determine correlations. Two-tailed Spearman rank correlation coefficients were obtained, along with the associated $P$ value.

\section{Results}

MCPyV viral load in skin from healthy volunteers

The presence of MCPyV DNA and virions on the skin of healthy volunteers has been demonstrated in several studies $[13-15,27]$. The high frequency at which the virus is found in the general population suggests that colonization/infection by the virus is probably both ubiquitous and chronic. In this study, swab specimens from two or three skin sites were tested for MCPyV DNA content by quantitative realtime PCR (qPCR), with the goal of determining whether the amount of MCPyV shed from the various sites was similar or different for a given individual. Subjects were sampled at various time points to determine whether the MCPyV DNA load remains constant through time.

Sixteen volunteers (cohort A) self-sampled at three skin sites: the back of the hand, the forehead, and the buttocks. A separate set of 33 volunteers (cohort B) were sampled at two skin sites (back of the hand and forehead). For each sample, the number of copies of MCPyV DNA was standardized to the number of copies of human beta-globin DNA. The MCPyV DNA load at a given anatomic site for a given individual showed no consistent trends over time. Some individuals (A12, B9, B23, B25, etc., Supplemental Table 1) showed remarkably stable loads in all anatomical sites over time, with data points differing by less than one log. In other individuals (B8, B16, B24, etc.), the MCPyV DNA levels at some anatomic sites were lower for the initial swab, then they increased by two or three logs at the second and/or third time point, only to come back to baseline levels by the end of the study (data not shown and Supplemental Table 1). Conversely, some individuals (A7, A9, B15, etc.) initially had a higher MCPyV load at one or more anatomic sites, followed by one or more swabs that declined by up to two logs, followed by swabs that were less than one $\log$ from the original sample. While a difference of two logs might seem large, the MCPyV DNA qPCR assay showed a dynamic range that spanned 7 orders of magnitude. Thus, when averaging the values for all the swabs for an individual, the standard deviation is relatively small (less than one log) as shown in Fig. 1. This suggests that, while viral loads may show occasional peaks or troughs over time, individual subjects generally remain within their quartile of MCPyV DNA load (negative, low, medium, or high) over the course of several months.

The average standardized MCPyV load for all time points for swabs taken from the dorsal surface of hands correlated strongly with the MCPyV load found on the forehead (Spearman's rho of 0.842, $P<0.0001$ ) (Fig. 1). Cohort A showed a similar positive monotonic correlation between samples from the hand and forehead (Spearman's rho of 0.667, $P=0.005$ ) (Supplemental Figure 1). For cohort A, where three different skin sites were sampled, a similar high degree of monotonic correlation was observed for MCPyV DNA load on individuals' hands versus buttocks (Spearman rho $=0.768, P<0.001$ ) or buttocks versus forehead (Spearman rho $=0.627, P=0.009$ ) (Supplemental Figure 1). The results show that, for a given individual, the amount of shed MCPyV DNA is similar at multiple anatomic sites.

Only three volunteers $(6 \%)$ were negative for MCPyV for all swabs at all time points in both cohorts. Sixteen

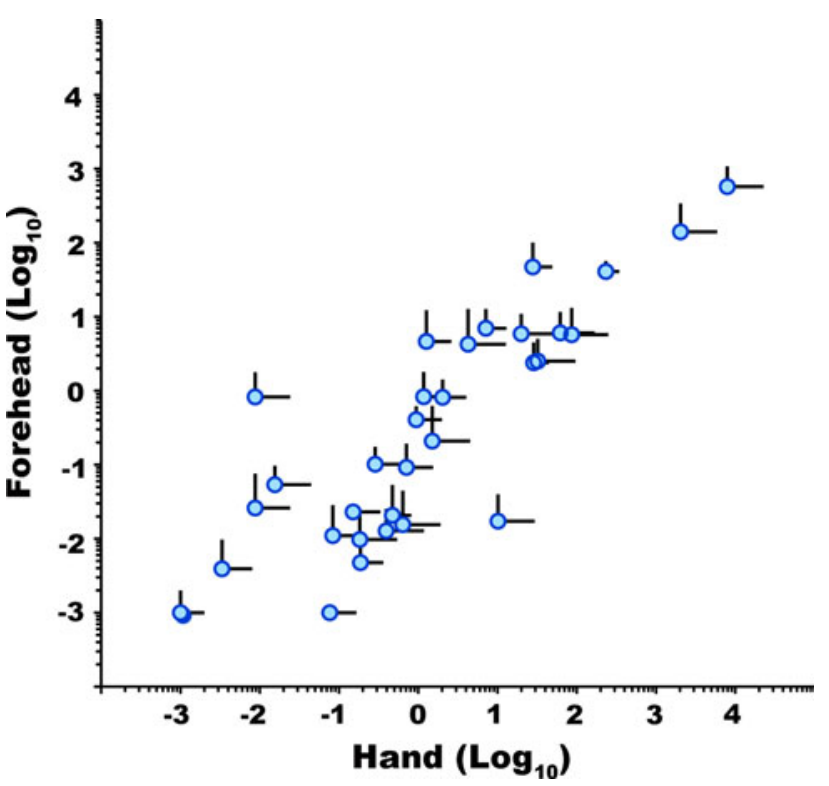

Fig. 1 Comparison of MCPyV DNA load at two anatomical sites for the 33 subjects in cohort $\mathrm{B}$. Each data point reflect the average MCPyV DNA load (expressed as copies of MCPyV DNA per copy of human beta-globin DNA) observed in skin swab specimens taken from the dorsum of the hand ( $x$-axis) or the forehead ( $y$-axis) at four time points. Error bars depict one standard deviation. Two samples overlap at coordinates $x=0.001, \mathrm{y}=0.001$ 
volunteers (33\%) were positive for all swabs at all the anatomical sites tested (in cohort A, 1 volunteer was only sampled once). Within the uniformly positive group, MCPyV could be detected at a 4-fold excess over betaglobin in at least one swab. The highest level of MCPyV detected was in a volunteer who had more than 1,000 copies of MCPyV per copy of beta-globin in two consecutive hand swabs and one forehead swab (subject ID B8, Supplemental Table 1). There was no apparent correlation between the age of the volunteers and the MCPyV DNA load (Supplemental Figure 2). Also, there were no evident differences between men and women in MCPyV DNA load (Supplemental Table 1).

MCPyV-specific antibody responses

We used a previously reported serological assay that measures MCPyV capsid-specific antibodies capable of neutralizing the infectivity of an MCPyV-based reporter vector (pseudovirus). The majority (80\%) of volunteers had detectable MCPyV capsid-specific antibody responses. The geometric mean $50 \%$ neutralizing serum dilution $\left(\mathrm{EC}_{50}\right)$ for all subjects in the study was 3,800. The results are consistent with previous studies of healthy adult populations [3]. A subset of 31 volunteers contributed two serum samples 11-15 months apart. In most instances, the neutralizing $\mathrm{EC}_{50}$ values for the two time points differed by less than two-fold (Fig. 2 and Supplemental Figure 4). There was only a marginal correlation between the age of the volunteers and $\mathrm{MCPyV}$-specific serum neutralizing titer (Spearman's rho of $0.3101, P=0.0301$ ); however, the correlation might not be apparent because the sample population was biased toward the $3 \mathrm{rd}$ and 4 th decades of life ( $60 \%$ of volunteers are in this category). There were no apparent differences between men and women in MCPyV serum titers (Supplemental Table 1).

\section{Correlation between MCPyV DNA load and MCPyV- specific antibody response}

In this part of the study, we aimed to examine whether there was a correlation between an individual subject's anti-MCPyV antibody titer and their MCPyV viral load.

Comparison of individual subjects' overall viral load (average of all time points for all anatomical sites) to their average serological titer revealed a strong positive monotonic correlation (Spearman rho 0.644, $P<0.0001$ ) (Fig. 3). Although there was a strong positive monotonic correlation between MCPyV load and MCPyV-neutralizing antibody responses for the population as a whole, there was one person with a neutralizing titer of about 7,000 but no detectable virus in any swab (ID B20, Supplemental Table 1). Conversely, a set of four individuals (ID = A1,

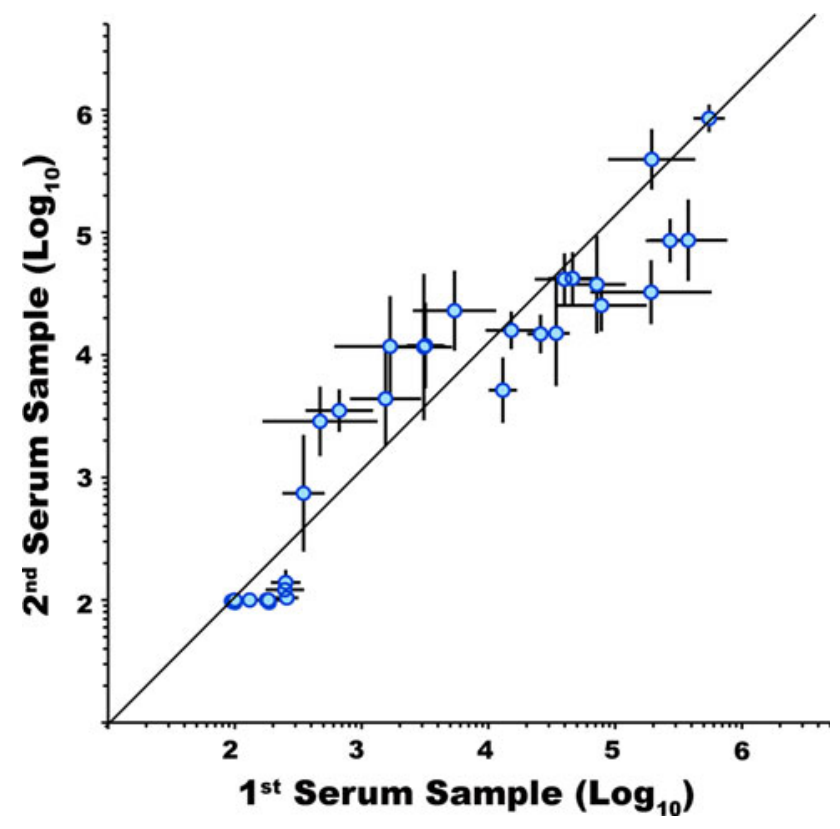

Fig. 2 Stability of MCPyV-specific antibody titers. Sera were obtained from 31 volunteers at two time points 11-15 months apart. Samples were serially diluted and used in a MCPyV reporter vectorbased neutralizing assay. The plot shows the $50 \%$ neutralizing titer $\left(\mathrm{EC}_{50}\right)$ for each subject's initial ( $x$-axis) versus repeat ( $y$-axis) serum sample. Error bars depict the $95 \%$ confidence interval. Four samples overlap at coordinates $x=100, y=100$; two samples overlap at coordinates $x=178$ (184), $y=100$; and two samples overlap at coordinates $x=3,098(3,182), y=11,935(11,600)$

B3, B21, B24, Supplemental Table 1) displayed low or undetectable serological responses despite rather high mean MCPyV DNA loads (2-46 copies per copy of betaglobin). In three (ID = B3, B21, B24) of the four individuals, these average loads were due to high values in single swabs, and the moderate average loads for the remaining swabs were $3.3,0.001$, and 0.2 versus $46.0,4.3$, and 5.1, respectively.

Beta-globin was used to normalize the MCPyV DNA loads, as the closest available proxy for how many epithelial cells were captured in the swab specimen. However, the virus could also be extracellular or associated with squamous cells devoid of DNA [15], and thus viral load less dependent on the number of intact epithelial cells in the swab. To address this aspect, we compared the unstandardized MCPyV DNA load to MCPyV-neutralizing titers. This data also showed a positive monotonic correlation (Spearman rho 0.696, $P<0.0001$ ) that was very similar to the beta-globin normalized data (Supplemental Figure 3).

\section{Discussion}

The data presented in this report support two general conclusions. The first conclusion is that nearly all healthy 


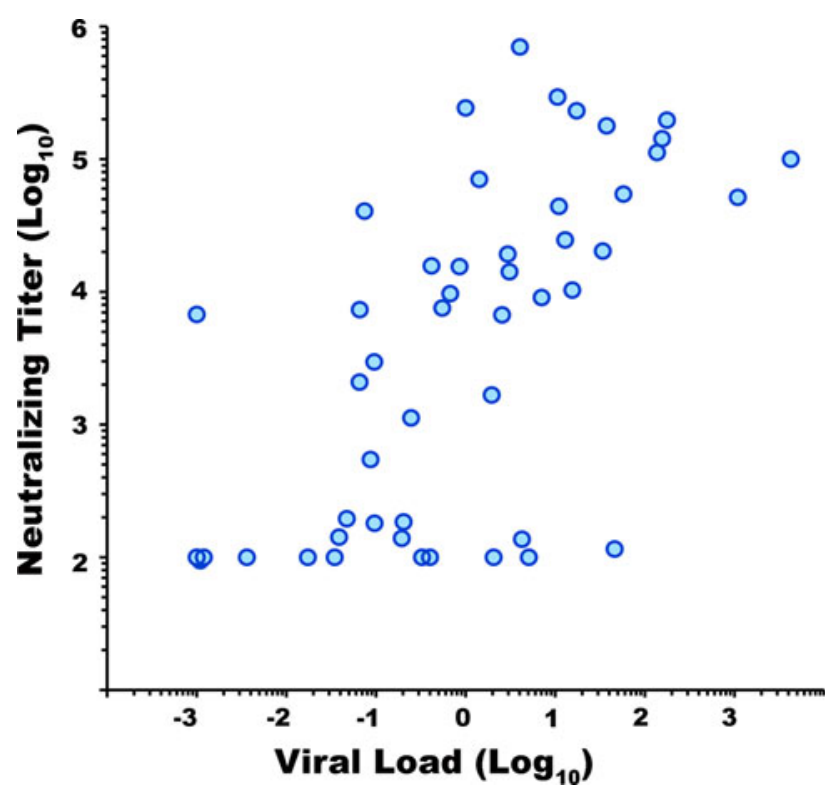

Fig. 3 Correlation between viral load and anti-MCPyV-neutralizing titer. For each of the 49 volunteers, the normalized MCPyV DNA load was averaged for all the anatomical sites (foreheads, hands and, when available, buttocks) at all time points (1-10 time points spanning 0 months to 4 years). For the neutralizing titer, the average $\mathrm{EC}_{50}$ from two serum collections was plotted, when available. Two samples overlap at coordinates $x=0.001, y=100$

individuals chronically shed MCPyV DNA, likely in the form of virions [15], from the surface of their skin. A second conclusion is that the amount of MCPyV DNA that is chronically shed from the skin is typically reflected in the magnitude of a subject's serum antibody responsiveness to the MCPyV capsid. This is consistent with the concept that the skin is a primary reservoir of productive $\mathrm{MCPyV}$ infection, although it does not exclude the possibility that there might be additional sites of MCPyV infection.

In this study, individual subjects were found to shed similar amounts of MCPyV DNA from their hands, foreheads, and buttocks, suggesting that MCPyV infection is typically widespread over various skin surfaces. The hands and face typically come into contact several times per hour [28], which could increase the degree of correlation in the surface MCPyV load for these sites. However, strong correlations were also observed between the MCPyV loads on each individual's forehead and buttocks, as well as on their hands and buttocks. Thus, the results indicate that the magnitude of a given individual's MCPyV burden is generally uniform across a range of environmentally exposed and unexposed skin areas. The mechanism through which productive $\mathrm{MCPyV}$ infections apparently persist despite robust anti-MCPyV antibody responses is unknown.

The lower limit of detection for the MCPyV neutralization assay has been previously discussed [3]. The limit was set at a serum dilution of 1:100 because that was the lowest dilution at which serum from unimmunized rabbits was less than $50 \%$ neutralizing. We consider this to be a conservative standard, particularly in light of the more recent concept that putatively naïve laboratory rabbits might be environmentally exposed to $\mathrm{MCPyV}$ virions shed from the skin of their human handlers. It is likewise conceivable that low-level neutralizing antibody titers in humans could reflect environmental exposure to $\mathrm{MCPyV}$, as opposed to actual infection. In this manuscript, for graphing purposes, all volunteers that did not reach an $\mathrm{EC}_{50}$ at a dilution of 1:100 were assigned a titer of 100 . However, the actual MCPyV-specific titers of these subjects could theoretically be much lower, or even non-existent. These limitations restrict the power of the correlation between serum titer and viral load at the lower end of the spectrum. Consistent with this idea, the correlation between viral load and antibody titer was substantially stronger at the high end of the spectrum.

There were a few specific exceptions to the correlation between viral load and antibody titers. Study volunteer B20 showed no detectable virus in all eight of the skin swab specimens but nevertheless showed a relatively high serological titer $(1: 6,700)$. It is conceivable that this person developed an immune response that resulted in clearance of the MCPyV infection. Another possible explanation would be that the subject carries an MCPyV infection that is localized to skin, mucosal surfaces, or other anatomical sites that were not sampled in the current study. Four individuals with moderate viral loads displayed either undetectable or very low levels of anti-MCPyV antibodies. This may indicate that some individuals are not able to mount (or have simply not yet mounted) a humoral immune response, despite ongoing or episodic MCPyV infection. To begin to examine the concept that antibody responses associated with moderate levels of MCPyV shedding are very slow to develop, we stratified volunteers for whom two serological time points were available into quartiles according to their viral load. Subjects in the bottom three quartiles of viral load seemed to show a general trend toward increasing antibody titers over the 11-15 months sampling interval (Supplemental Figure 4). In contrast, subjects in the top quartile of viral load appeared to show slightly decreasing titers. The concept that MCPyV-specific antibody responses may be mounted over the course of many years could partially explain the relatively weaker correlation between antibody titer and $\mathrm{MCPyV}$ viral load for individuals in the middle and lower end of the spectrum. Obtaining a clearer answer to the question of the kinetics of the induction of B cell responses against the $\mathrm{MCPyV}$ will likely require analysis of serum samples collected over much longer time periods.

High titer MCPyV capsid-specific antibody responses can be found in both the normal human population and in 
MCC patients [3]. However, the geometric mean MCPyV-neutralizing titer of individuals with MCC is about 60-fold higher compared to healthy controls. In light of the data reported in the current study, it seems likely that the unusually high MCPyV-specific serological titers in MCC patients reflect a history of unusually high MCPyV viral load in these subjects' skin. An implication of this model could be that poorly controlled MCPyV infection might be one of the risk factors for development of MCC.

It is not yet clear whether MCPyV is associated with additional human diseases beyond MCC. Other potential MCPyV-associated disease states might, like MCC, be associated with unusually high levels of MCPyV DNA on the surface of the skin and/or unusually strong MCPyVspecific seroresponses.

Acknowledgments This work was funded in part by the Intramural Research Program of the NIH, with support from the Center for Cancer Research and the NCI Director's Intramural Innovation Award Program, and in part by the German National Reference Center for Papilloma- and Polyomaviruses (German Federal Ministry of Health, grant number FKZ 1369-401).

Ethical standards The experiments comply with the current laws of the countries (United States of America and Germany) in which they were performed.

Open Access This article is distributed under the terms of the Creative Commons Attribution Noncommercial License which permits any noncommercial use, distribution, and reproduction in any medium, provided the original author(s) and source are credited.

\section{References}

1. Feng H, Shuda M, Chang Y, Moore PS (2008) Clonal integration of a polyomavirus in human Merkel cell carcinoma. Science 319(5866): 1096-1100

2. Tolstov YL, Pastrana DV, Feng H, Becker JC, Jenkins FJ, Moschos S, Chang Y, Buck CB, Moore PS (2009) Human Merkel cell polyomavirus infection II. MCV is a common human infection that can be detected by conformational capsid epitope immunoassays. Int J Cancer 125(6):1250-1260

3. Pastrana DV, Tolstov YL, Becker JC, Moore PS, Chang Y, Buck CB (2009) Quantitation of human seroresponsiveness to Merkel cell polyomavirus. PLoS Pathog 5(9):1000578. doi:10.1371/ journal.ppat.1000578

4. Carter JJ, Paulson KG, Wipf GC, Miranda D, Madeleine MM, Johnson LG, Lemos BD, Lee S, Warcola AH, Iyer JG, Nghiem P, Galloway DA (2009) Association of Merkel cell polyomavirusspecific antibodies with Merkel cell carcinoma. J Natl Cancer Inst 101(21):1510-1522. doi:10.1093/jnci/djp332

5. Kean JM, Rao S, Wang M, Garcea RL (2009) Seroepidemiology of human polyomaviruses. PLoS Pathog 5(3):e1000363. doi: 10.1371/journal.ppat.1000363

6. Boldorini R, Veggiani C, Barco D, Monga G (2005) Kidney and urinary tract polyomavirus infection and distribution: molecular biology investigation of 10 consecutive autopsies. Arch Pathol Lab Med 129(1):69-73

7. Hogan TF, Padgett BL, Walker DL, Borden EC, McBain JA (1980) Rapid detection and identification of JC virus and BK virus in human urine by using immunofluorescence microscopy. J Clin Microbiol 11(2):178-183

8. Singh HK, Bubendorf L, Mihatsch MJ, Drachenberg CB, Nickeleit V (2006) Urine cytology findings of polyomavirus infections. Adv Exp Med Biol 577:201-212. doi:10.1007/0-38732957-9_15

9. Chesters PM, Heritage J, McCance DJ (1983) Persistence of DNA sequences of BK virus and JC virus in normal human tissues and in diseased tissues. J Infect Dis 147(4):676-684

10. Heritage J, Chesters PM, McCance DJ (1981) The persistence of papovavirus BK DNA sequences in normal human renal tissue. J Med Virol 8(2):143-150

11. Kitamura T, Aso Y, Kuniyoshi N, Hara K, Yogo Y (1990) High incidence of urinary JC virus excretion in nonimmunosuppressed older patients. J Infect Dis 161(6):1128-1133

12. Zhong S, Zheng HY, Suzuki M, Chen Q, Ikegaya H, Aoki N, Usuku S, Kobayashi N, Nukuzuma S, Yasuda Y, Kuniyoshi N, Yogo Y, Kitamura T (2007) Age-related urinary excretion of BK polyomavirus by nonimmunocompromised individuals. J Clin Microbiol 45(1):193-198. doi:10.1128/JCM.01645-06

13. Wieland U, Mauch C, Kreuter A, Krieg T, Pfister H (2009) Merkel cell polyomavirus DNA in persons without merkel cell carcinoma. Emerg Infect Dis 15(9):1496-1498

14. Loyo M, Guerrero-Preston R, Brait M, Hoque M, Chuang A, Kim M, Sharma R, Liegeois N, Koch W, Califano J, Westra W, Sidransky D (2010) Quantitative detection of merkel cell virus in human tissues and possible mode of transmission. Int J Cancer 126(12):2991-2996. doi:10.1002/ijc.24737

15. Schowalter RM, Pastrana DV, Pumphrey KA, Moyer AL, Buck CB (2010) Merkel cell polyomavirus and two previously unknown polyomaviruses are chronically shed from human skin. Cell Host Microbe 7(6):509-515. doi:10.1016/j.chom.2010.05.006

16. Bohl DL, Storch GA, Ryschkewitsch C, Gaudreault-Keener M, Schnitzler MA, Major EO, Brennan DC (2005) Donor origin of BK virus in renal transplantation and role of HLA C7 in susceptibility to sustained BK viremia. Am J Transplant 5(9):22132221. doi:10.1111/j.1600-6143.2005.01000.x

17. Randhawa P, Bohl D, Brennan D, Ruppert K, Ramaswami B, Storch G, March J, Shapiro R, Viscidi R (2008) longitudinal analysis of levels of immunoglobulins against BK virus capsid proteins in kidney transplant recipients. Clin Vaccine Immunol 15(10):1564-1571

18. Lundstig A, Stattin P, Persson K, Sasnauskas K, Viscidi RP, Gislefoss RE, Dillner J (2007) No excess risk for colorectal cancer among subjects seropositive for the JC polyomavirus. Int $\mathrm{J}$ Cancer 121(5): 1098-1102

19. Besson C, Amiel C, Le-Pendeven C, Brice P, Ferme C, Carde P, Hermine O, Raphael M, Abel L, Nicolas JC (2006) Positive correlation between Epstein-Barr virus viral load and anti-viral capsid immunoglobulin G titers determined for Hodgkin's lymphoma patients and their relatives. J Clin Microbiol 44(1):47-50. doi:10.1128/JCM.44.1.47-50.2006

20. Morand-Joubert L, Mariotti M, Reed D, Petit JC, Lefrere JJ (1995) Correlation between viral DNA load and serum anti p19 antibody concentration in symptomless human T-lymphotropic virus type-I (HTLV-I)-infected individuals. Int $\mathrm{J}$ Cancer 60(2): 156-159

21. Hung IF, To KK, Lee CK, Lin CK, Chan JF, Tse H, Cheng VC, Chen H, Ho PL, Tse CW, Ng TK, Que TL, Chan KH, Yuen KY (2010) Effect of clinical and virological parameters on the level of neutralizing antibody against pandemic influenza A virus H1N1 2009. Clin Infect Dis 51(3):274-279. doi:10.1086/653940 
22. Duh D, Saksida A, Petrovec M, Ahmeti S, Dedushaj I, Panning M, Drosten C, Avsic-Zupanc T (2007) Viral load as predictor of Crimean-Congo hemorrhagic fever outcome. Emerg Infect Dis 13(11):1769-1772

23. Pestka JM, Zeisel MB, Blaser E, Schurmann P, Bartosch B, Cosset FL, Patel AH, Meisel H, Baumert J, Viazov S, Rispeter K, Blum HE, Roggendorf M, Baumert TF (2007) Rapid induction of virus-neutralizing antibodies and viral clearance in a singlesource outbreak of hepatitis C. Proc Natl Acad Sci USA 104(14):6025-6030. doi:10.1073/pnas.0607026104

24. Weissenborn SJ, De Koning MN, Wieland U, Quint WG, Pfister HJ (2009) Intrafamilial transmission and family-specific spectra of cutaneous betapapillomaviruses. J Virol 83(2):811-816. doi: 10.1128/JVI.01338-08
25. Sihto H, Kukko H, Koljonen V, Sankila R, Bohling T, Joensuu H (2009) Clinical factors associated with Merkel cell polyomavirus infection in Merkel cell carcinoma. J Natl Cancer Inst 101(13):938-945. doi:10.1093/jnci/djp139

26. Buck CB, Pastrana DV, Lowy DR, Schiller JT (2004) Efficient intracellular assembly of papillomaviral vectors. J Virol 78(2):751-757

27. Foulongne V, Kluger N, Dereure O, Mercier G, Moles JP, Guillot B, Segondy M (2010) Merkel cell polyomavirus in cutaneous swabs. Emerg Infect Dis 16(4):685-687

28. Nicas M, Best D (2008) A study quantifying the hand-to-face contact rate and its potential application to predicting respiratory tract infection. J Occup Environ Hyg 5(6):347-352. doi:10.1080/ 15459620802003896 